Asma Nouira*, Jihen Maatoug, Imed Harrabi, Sonia Hmad, Mmyléne Belkacem, Slim Slama, Mustafa al'Absi, Harry Lando and Hassen Ghannem

\title{
Clustering of risk factors in the smoking habits of schoolchildren in Sousse, Tunisia
}

\begin{abstract}
Background: In Tunisia, little is known about the association between tobacco use and other chronic disease risk factors. This is the case for both adults and children. It is important to know the characteristics of young smokers to facilitate the creation and implementation of future programs for tobacco prevention.

Aim: The aim of this study was to determine the association between tobacco use and other lifestyle factors among schoolchildren in Tunisia.
\end{abstract}

Methods: We conducted a 2009/2010 cross-sectional questionnaire survey of 4003 randomly selected school children aged 13 years old (7th and 9th grades) to evaluate their knowledge, attitudes towards, and beliefs about the three risk factors for chronic disease (unhealthy diet, physical inactivity, and tobacco use). Written informed consent was obtained from each child's parents who allowed their child to participate.

Results: The mean age of our sample was $13.36 \pm 1.28$ years. The proportions of daily smokers were $2.2 \%$ and $0.1 \%$ among boys and girls, respectively. The proportions of irregular smokers were $9.1 \%$ and $1.5 \%$ among boys and girls, respectively. In our population, 19.1\% $(n=767)$ had ever experimented to smoke, with $29.8 \%$ among boys and $9 \%$ among girls $(\mathrm{p}<0.001)$. The proportions of schoolchildren who reported daily participation in physical activity were different between smokers and nonsmokers with $17.7 \%$ and $11.5 \%$, respectively $(\mathrm{p}=0.03)$. Concerning eating habits, there was no significant difference in the consumption of fruits and vegetables; however, smokers frequently ate more high fat foods and in fast food restaurants. Similar results were found while comparing regular smoking children with those who experimented but who never became hooked on smoking.

Conclusion: This study and previous research suggest the importance of early intervention in adolescents on smoking and combing these efforts with interventions focusing on physical activity and dietary habits.

Keywords: risk factors; smoking habits; schoolchildren.

\author{
*Corresponding author: Asma Nouira, Department of Epidemiology, \\ University Hospital Farhat Hached, Sousse, Tunisia, \\ E-mail:asma_nouira@yahoo.fr \\ Jihen Maatoug, Imed Harrabi, Sonia Hmad, Mmyléne Belkacem and \\ Hassen Ghannem: Department of Epidemiology, University Hospital \\ Farhat Hached, Sousse, Tunisia \\ Slim Slama: Department of Community Medicine, Primary care and \\ Emergency, University Hospitals of Geneva, Switzerland \\ Mustafa al'Absi: Duluth Medical Research Institute, University of \\ Minnesota, MN, USA \\ Harry Lando: Department of Epidemiology and Community Health, \\ University of Minnesota, MN, USA
}

\section{Introduction}

Smoking is a public health problem and an obstacle to the development of many countries in the world (1). The World Health Organization (WHO) reports that tobacco kills 13,000 people every day (2) and estimates that there are 6 million smoking-related deaths each year (3). This is a major concern in Tunisia where a combination of cigarette smoking, poor diet, and physical inactivity is prevalent among adolescents; these have also been identified as major contributors to preventable morbidity and mortality $(4,5)$. These behaviors continue into adulthood and increase the risk of heart disease, stroke, certain cancers, and other chronic diseases (6).

Previous study about tobacco use among adolescents indicated that the prevalence of tobacco use is on the rise, with the age of initiation becoming earlier (2). If the trend continues, smoking will be responsible for the death of 250 million children (7). There have been several studies about the dietary habits of smokers worldwide (8). However, in Tunisia, no study has focused on the association between tobacco consumption and the concomitance of other chronic diseases risk factors.

It is important to identify patterns of risk factors among young smokers in order to inform future efforts for tobacco prevention. In relation to this, the clustering of risk factors has been shown to be a better predictor of cardiovascular health in children than single risk factors (9-11). The aim of the current study was to determine 
the association between tobacco use and other lifestyle factors among schoolchildren in Tunisia.

\section{Materials and methods}

\section{Study design}

This study was part of an assessment of the prevalence of chronic disease risk factors in a community-based intervention program (with school component), which was conducted in 2009 in the region of Sousse, Tunisia. We carried out a cross-sectional survey in 2009/2010. The targeted population was schoolchildren in the 7th and 9 th grades aged between 12 and 14 years.

\section{Study population}

The study involved pupils of colleges of Sousse in the 7th and 9th grades. The sample of 4003 schoolchildren consisted of randomly selected students from all colleges of the delegations of Sousse Jawhara, Sousse Erriadh and M'saken, which represented 16 colleges.

\section{Data collection}

We used the questionnaire elaborated by the Oxford Health Alliance for community intervention for health. It was translated to Arabic and underwent pretesting. The self-administered questionnaire was used to evaluate knowledge, attitudes towards, and beliefs on the three risk factors for chronic disease, namely, unhealthy diet, physical inactivity and tobacco use. The questionnaire was administered in classes with the presence of trained medical doctors, who assisted the children as they answered the questionnaires.

Anthropometric measurements of height, weight, and waist circumference were obtained from each participant during interview and clinical examination using a standardized protocol. Body weight was recorded to the nearest $0.1 \mathrm{~kg}$ using a portable electronic scale. Standing height was measured with the participants in bare feet to the nearest $0.5 \mathrm{~cm}$. waist circumference was measured to the nearest $0.1 \mathrm{~cm}$ using a non-stretchable standard tape measure. The measurement was taken over a light article of clothing, at the smallest diameter between the costal margin and the iliac crest.

\section{Statistical analysis}

The mean \pm standard deviation value was calculated for continuous variables and the percentage of each subgroup for the categorical variables. Comparisons between two group means were performed using the t-test. Associations between categorical variables were tested using the $\chi^{2}$ test. All data analyses were conducted using SPSS 10.0 statistical software. All statistical tests were two-tailed, and $\mathrm{p}<0.05$ was considered statistically significant.

\section{Ethical consideration}

Due to the young age of the studied population, this investigation was undertaken with due respect for the rights and the integrity of people. Parents gave their consent and were allowed to refuse their child's participation. We used an anonymous questionnaire that did not contain the name or the address of schoolchildren.

\section{Results}

The global response rate was $94.5 \%$. The studied population consisted of 4003 schoolchildren. The sex ratio was 1.07 ( $48.3 \%$ boys vs. $51.7 \%$ girls). The mean age of our population was $13.36 \pm 1.28$ years. After evaluating the smoking habits of the participants, we found that the proportions of daily smokers were $2.2 \%$ and $0.1 \%$ among boys and girls, respectively. The proportions of irregular smokers were $9.1 \%$ and $1.5 \%$ among boys and girls, respectively. The proportion of daily smokers was higher among boys with a significant difference $(\mathrm{p}<0.001)$ (Table 1$)$. The average age of experimentation was 10.61 \pm 3.14 years, with $10.77 \pm 3.07$ among boys and 10.10 \pm 3.91 among girls.

\section{Differences between smokers and non-smokers in their demographics and other behavioral habits}

Only $11.9 \%$ of schoolchildren reported practicing physical activity daily (Table 2). This proportion was different between smokers and non-smokers with $17.7 \%$ and $11.5 \%$, respectively $(\mathrm{p}=0.03)$. Next, we explored sedentary activities among schoolchildren by evaluating their screen times during weekdays and the number of days per week that they go to school on foot or by bike. The proportion of schoolchildren who spent more than $2 \mathrm{~h}$ of screen time per day in a weekday is significantly higher among smokers (67.6\% vs. $55.3 \%)$. We did not find a significant difference between smokers and non-smokers concerning the number of days per week that sampled children go to school on foot or by bike.

Table 1 Distribution of schoolchildren according to their smoking profiles.

\begin{tabular}{lrrrr}
\hline & Male n (\%) & Female n (\%) & Total n (\%) & p-Value \\
\hline Non-smokers & $1705(88.7)$ & $2033(98.5)$ & $3738(93.8)$ & $<0.001$ \\
Irregular smokers & $175(9.1)$ & $31(1.5)$ & $206(5.2)$ & $<0.001$ \\
Regular smokers & $42(2.2)$ & $1(0.1)$ & $43(1.1)$ & $<0.001$ \\
\hline
\end{tabular}


Table 2 Distribution of schoolchildren's physical activity habits according to smoking status.

\begin{tabular}{|c|c|c|c|c|}
\hline & Non-smokers & Smokers & Total & p-Value \\
\hline Does the recommended physical activity $\mathrm{n}(\%)$ & $429(11.5)$ & $44(17.7)$ & $473(11.9)$ & 0.03 \\
\hline Weekday screen time $>2$ h per day $n(\%)$ & $2046(55.3)$ & $165(67.6)$ & $2211(56.1)$ & $<0.001$ \\
\hline $\begin{array}{l}\text { Number of days per week that you go to } \\
\text { school on foot or by bike mean (SD) }\end{array}$ & $4.82(2.1)$ & $4.8(2.1)$ & $4.8(2.1)$ & 0.86 \\
\hline
\end{tabular}

Concerning eating habits (Table 3), schoolchildren reported the following frequencies (number of days per week) of consuming various foods, which did not vary between non-smokers and smokers: vegetables, 4.37 days/week and 4.31 days/week ( $\mathrm{p}=0.73$ ); fruits, 5.58 days/ week and 5.35 days/week ( $\mathrm{p}=0.08$ ); high fat food, 2.43 days/week and 3.38 days/week ( $<<0.001)$; foods high in salt, 2.92 days/week and 3.37 days/week $(\mathrm{p}=0.03)$; and eating at a fast food restaurant, 1.58 days/week and 2.46 days/week $(\mathrm{p}<0.001)$, respectively. We also evaluated the serving of fruits ( $2.71 \mathrm{vs.} 2.77, \mathrm{p}=0.44)$ and vegetables $(2.37$ vs. 2.64, $\mathrm{p}=0.07$ ) consumed per day.

\section{Differences between children who experimented and continued to smoke vs. those who experimented and never got hooked on the habit}

In our population, 19.1\% $(\mathrm{n}=767)$ had experimented with smoking, with $29.8 \%$ among boys and $9 \%$ among girls $(\mathrm{p}<0.001)$. The average ages of experimentation were $12.03 \pm 2.53$ years for schoolchildren who maintained smoking, and $9.92 \pm 3.18$ years for those who quit smoking after their first try and became non-smokers $(\mathrm{p}<0.001)$.

We found that only $16.6 \%$ of schoolchildren who had experimented with cigarettes reported practicing physical activity daily. This proportion was not different between those who remained as non-smokers and those who became smokers with $16.4 \%$ and $17.2 \%$, respectively $(\mathrm{p}=0.79)$.
Next, we explored the sedentary activities among schoolchildren by evaluating their screen times in weekdays and by identifying the number of days per week that they go to school on foot or by bike. We did not find a significant difference between schoolchildren who experimented and continued to smoke and those who experimented and never got hooked on the habit (Table 4).

Concerning eating habits, we found that schoolchildren who regularly smoked more frequently ate high saturated fat food than non-smokers (2.63/week vs. 3.33/week, $\mathrm{p}<0.001$ ) and visited fast food restaurants more frequently (1.83/week vs. $2.44 /$ week). The latter was an association that was statistically significant $(p<0.001)$ (Table 5).

\section{Discussion}

Tobacco use is more frequent among adolescents and continues until adulthood. An inadequate diet and physical inactivity may compound the deleterious effects of smoking on health. For example, research indicates that adolescents who smoke may be less likely to exercise or to consume adequate amounts of calcium-rich foods and beverages (8). Observational studies examining patterns of health behavior covariations in adolescents have related smoking behavior to irregular meal patterns (12), greater intakes of soft drinks, and lower intakes of fruits, vegetables, and dairy foods (8, 13-15). In addition, findings from cross-sectional and longitudinal research suggest an inverse relationship between physical activity and cigarette smoking during adolescence $(8,16)$.

Table 3 The schoolchildrens' eating habits according to their smoking status.

\begin{tabular}{lrrr}
\hline & Non-smokers & Smokers & p-Value \\
\hline Serving of fruits consumed per day & $2.71 \pm 1.29$ & $2.77 \pm 1.31$ & 0.44 \\
Serving of vegetables consumed per day & $2.37 \pm 1.46$ & $2.64 \pm 1.53$ & 0.07 \\
Number of days per week where you eat vegetables & $4.37 \pm 2.4$ & $4.31 \pm 2.32$ & 0.73 \\
Number of days per week where you eat fruits & $5.58 \pm 1.99$ & $5.35 \pm 2.12$ & 0.08 \\
Number of days per week that you eat foods high in fat & $2.43 \pm 2.03$ & $3.38 \pm 2.34$ & $3.37 \pm 2.5$ \\
Number of days per week that you eat foods high in salt & $2.92 \pm 2.34$ & $2.46 \pm 2.11$ & 0.001 \\
Number of days per week where you eat at a fast food & $1.58 \pm 1.82$ & $<0.001$ \\
\hline
\end{tabular}


Table 4 Distribution of schoolchildren's physical activity habits according to smoking status after the first experimentation.

\begin{tabular}{|c|c|c|c|c|}
\hline & Remained as non-smokers & Remained as smokers & Total & p-Value \\
\hline Does the recommended physical activity $\mathrm{n}(\%)$ & $84(16.4)$ & $41(17.2)$ & $125(16.6)$ & 0.79 \\
\hline Weekday screen time $>2$ h per day $n(\%)$ & $327(63.7)$ & $160(68.1)$ & $487(65.1)$ & 0.28 \\
\hline $\begin{array}{l}\text { Number of days per week that you go to school on } \\
\text { foot or by bike mean (SD) }\end{array}$ & $5.02(1.9)$ & $4.79(2.1)$ & $4.9(2.0)$ & 0.15 \\
\hline
\end{tabular}

Table 5 The schoolchildren's eating habits according to their smoking status after the first experimentation.

\begin{tabular}{|c|c|c|c|}
\hline & Remained as non-smokers & Remained as smokers & p-Value \\
\hline Serving of fruits consumed per day & $2.92 \pm 1.24$ & $2.76 \pm 1.29$ & 0.12 \\
\hline Serving of vegetables consumed per day & $2.52 \pm 1.51$ & $2.62 \pm 1.53$ & 0.39 \\
\hline Number of days per week where you eat vegetables & $4.49 \pm 2.42$ & $4.4 \pm 2.36$ & 0.65 \\
\hline Number of days per week where you eat fruits & $5.74 \pm 2.02$ & $5.35 \pm 2.12$ & 0.48 \\
\hline Number of days per week that you eat foods high in fat & $2.63 \pm 2.15$ & $3.33 \pm 2.31$ & $<0.001$ \\
\hline Number of days per week that you eat foods high in salt & $3.15 \pm 2.36$ & $3.37 \pm 2.52$ & 0.24 \\
\hline Number of days per week where you eat at a fast food & $1.83 \pm 1.90$ & $2.44 \pm 2.09$ & $<0.001$ \\
\hline
\end{tabular}

It is in this context that we attempted to examine how smoking is related to physical activity patterns, eating behaviors, and diet within a diverse, populationbased sample of adolescents. One of the main strengths of this study is that it assessed the clustering of lifestyle-related risk factors, which are usually studied in isolation.

Nevertheless, the findings in this report are subject to different limits. We evaluated tobacco use among adolescents across schools, because it included the majority of adolescents at this age. However, in this study, we did not include non-schooled children and those who were enrolled in private schools. The data collected applied only to youth who were in school on the day of the survey and who completed the questionnaire. However, the response rate of the schoolchildren was high, thereby suggesting that bias attributable to absence or non response was limited. The data were based on self-assessment of schoolchildren, which could under or overestimate their behaviors or attitudes owing to the taboos surrounding tobacco use at this age. To minimize this bias, we used anonymous questionnaires, and data collectors put participants at ease, explaining to them that the data analysis would be conducted anonymously. The way that the risk factors were measured also represented a limitation, because these were according to what schoolchildren reported and were not measured objectively owing to financial constraints met by the authors.

Smoking is a global problem, and it is estimated that among 82,000 and 99,000 young people who light up their first cigarette each day, many of them are children under 10 years, and they reside mostly in countries with low and middle incomes, respectively (17). In France, in 2005 , the prevalence rates of smoking are $8.6 \%$ and $34.2 \%$ among youth aged 12 to 15 and 16 to 19 years (18).

Tunisian recent studies have shown that smoking is a widespread habit among our youth. According to studies conducted by the direction of school and university medicine of Tunisia in 2002, the proportions of smokers among 4172 adolescents aged $12-20$ years are $55.8 \%$ for boys and $17.7 \%$ for girls (19). These rates are substantially higher than the prevalence found in the current study, although the current study included individuals at the younger end of this broad age range.

The Global Youth Tobacco Survey (GYTS), which was conducted in 2007 among a national sample of 2155 college educated 13-15 years in the 7th, 8th and 9th year grades, showed an overall prevalence of smoking by $8.9 \%$ with a male predominance (15.9\% vs. $2.0 \%)$ (20). Concerning an intervention study on smoking in schools conducted in the city of Sousse in 2007, 3.2\% of schoolchildren in the intervention group $(6.0 \%$ of boys and $0.8 \%$ girls) and $6.0 \%$ of schoolchildren in the control group $(12.0 \%$ of boys and $0.8 \%$ girls) were smokers (20). Our results reported similar numbers with prevalence rates of $11.3 \%$ and $1.6 \%$ among boys and girls who smoked cigarettes, respectively.

Smoking usually begins in adolescence, and appears to be linked to personal and psychological discomfort (21). Recent French surveys have noted a rejuvenation of the age of experimentation at the age of 11 years and 
a half (18). According to previous Tunisian studies, 17\% of schoolchildren (nearly a pupil in the 6th grade level) started smoking before the age of $13(2,19)$. In our study, the average age of experimentation was low (10.61 \pm 3.14 years), and schoolchildren who remained non-smokers had an age of experimentation that was lower than those who remained smokers. Thus, young people who started smoking at a later age are more likely to become smokers. This finding is intriguing, and the reasons that may account for this association between later initiation and maintenance of smoking are not known at this time.

Early smoking initiation is a major concern for the WHO, who reports that $25 \%$ to $33 \%$ of young people who experience smoking cigarettes become regular smokers and half of them in the year following the first initiation (22).

However, not all adolescents initiate smoking at the same time, with the same frequency, or with the same intensity. Many studies have investigated and characterized developmental smoking trajectories from adolescence to adulthood. For example, McGovern identified four adolescent smoking trajectories, namely, never smokers, experimenters, earlier/faster smoking adopters, and later/slower smoking adopters (21). Higher levels of disinhibition, poorer school performance, and more frequent use of alcohol and other drugs, increased the likelihood of being in a smoking trajectory over a non smoking trajectory. In addition, none of these risk factors distinguished between occasional and regular smokers (21, 23). Adolescent smoking prevention and intervention programs must, therefore, consider this heterogeneity and tailor or enhance attention to risk and protective factors depending on this population.

In this study, we described the association of cigarette smoking status with a range of lifestyle behaviors, including physical activity and eating patterns. Overall, we found that adolescents who smoked were more likely to engage in physical activity. This is in disagreement with other research that reported strong inverse associations between physical activity and smoking; this could mean that our findings did not support these studies due to measurement differences (24-26). Most other studies have considered frequency rather than total hours of weekly physical activity and have focused only on vigorous physical activity that makes one breathe hard $(8,27)$.

Observations indicating potential inverse association between smoking frequency and vigorous physical activity in adolescents are of particular concern because of two reasons: first, the tendency for physical activity to decline as adolescents transition to young adulthood, and second, because research has linked declining activity levels to increased BMI $(16,27)$. We observed associations between smoking and eating behaviors with greater consistency than associations between smoking and physical activity.

One finding among schoolchildren in our study was a direct association of smoking frequency with having unhealthy eating habits. This finding builds on previous studies that have reported similar associations between eating habits and smoking behavior in adolescents (28-31).

In interpreting the results of the current study, certain limitations should also be considered that may have interfered with our ability to observe the total effect of the associations among smoking, physical activity, and nutrition behaviors. For example, parents' level of education is a widely used indicator of socio-economic status, but the economic benefits of higher education are not uniform, and this indicator may have produced incomplete adjustment for socio-economic status. Despite efforts to further adjust associations for sex, grade level, and race and ethnicity, it is possible that factors other than the covariates included in our models contributed to the associations between smoking and patterns of poor diet and physical activity. This could have also influenced the observed pattern of associations. Alamian et al. (32) suggested that social distal variables (e.g., parental/peer smoking and peer drinking) and individual distal variables (e.g., low self-esteem) increased the rate of occurrence of multiple behavioral risk factors.

Finally, using only a single item to assess cigarette use may have led to some misclassification of smoking status. Misclassification would have attenuated associations of smoking with physical and sedentary activities, dietary patterns, and BMI. Additional measures of lifetime smoking habits would have allowed for analyses to consider whether established habitual patterns of smoking behavior are associated with unhealthy lifestyle behaviors.

Thus, future research should use more comprehensive measures of smoking behavior and use longitudinal study designs to clarify the temporal order of increases in smoking and decreases in healthy eating and activity behaviors.

\section{Conclusion}

This study and previous research suggest the importance of early intervention in adolescents on smoking, physical activity, and dietary patterns. One of the main strengths of this study is to assess the clustering of lifestyle-related risk factors, which are usually studied in isolation. Intensive 
efforts must be made to reduce smoking initiation among young people by integrating programs for health education generalized to all phases of school life.

Acknowledgment: The data collection and analysis was supported by a grant from the UnitedHealth Group. The manuscript writing and reviews were supported by an
NIH award, namely, the Fogarty International Center of the National Institutes of Health under Award Number R56TW009265.

Received March 9, 2013; accepted May 15, 2013; previously published online July 26, 2013

\section{References}

1. WHO report on the global tobacco epidemic (2008). The MPOWER package. Available at: www.who.int/tobacco/ mpower/mpower_report_full_2008.pdf.

2. Hamrouni M, Mokdad M. Le rapport de l'enquête nationale sur le tabagisme des jeunes scolarisés dans les écoles publiques, Mai 2007.

3. OTAF en collaboration avec la LNC et l'UICC. Enquêtes sur la prévalence du tabac et le comportement des jeunes vis-à-vis du tabac dans les pays francophones.

4. Ghannem H, Ben Abdelaziz A, Limam K, Gaha R, Ghedira A, et al. Tracking of cardiovascular risk factors among school children: a four-year population surveillance in Susa, Tunisia. Tunis Med 2005;83:404-8.

5. Harrabi I, Maatoug J, Gaha M, Kebaili R, Gaha R, et al. School-based intervention to promote healthy lifestyles in Sousse, Tunisia. Indian J Community Med 2010;35:94-9.

6. Larson NI, Story M, Perry CL, Neumark-Sztainer D, Hannan PJ. Are diet and physical activity patterns related to cigarette smoking in adolescents? Findings from Project EAT. Prev Chronic Dis 2007;4:A51.

7. Peto R, Lopez AD, Boreham J, Thun M, Heath C Jr, et al. Mortality from smoking worldwide. Br Med Bull 1996;52:12-21.

8. Wilson DB, Smith BN, Speizer IS, Bean MK, Mitchell KS, et al. Differences in food intake and exercise by smoking status in adolescents. Prev Med 2005;40:872-79.

9. Schuit AJ, van Loon AJ, Tijhuis M, Ocke M. Clustering of lifestyle risk factors in a general adult population. Prev Med 2002;35:219-24

10. Silva DA, et al. Clustering of risk behaviors for chronic noncommunicable diseases: a population-based study in southern Brazil. Prev Med 2013;56:20-24.

11. Andersen LB, Wedderkopp N, Hansen HS, Cooper AR, Froberg K. Biological cardiovascular risk factors cluster in Danish children and adolescents: the European heart study. Prev Med 2003;37:363-67.

12. Keski-Rahkonen A, Kaprio J, Rissanen A, Virkkunen M, Rose RJ. Breakfast skipping and health-compromising . behaviors in adolescents and adults. Eur J Clin Nutr 2003;57:842-53.

13. Baer Wilson D, Nietert PJ. Patterns of fruit, vegetable, and milk consumption among smoking and nonsmoking female teens. Am J Prev Med 2002;22:240-46.

14. Andersen LB, et al. Physical activity and clustered cardiovascular risk in children: a cross-sectional study (the European youth heart study). Lancet 2006;368:299-304.
15. Dumith SC, et al. Clustering of risk factors for chronic diseases among adolescents from Southern Brazil. Prev Med, 2012.

16. Paavola M, Vartiainen E, Haukkala A. Smoking, alcohol use, and physical activity: a 13-year longitudinal study ranging from adolescence into adulthood. J Adolesc Health 2004;35:238-44.

17. Mackay J, Eriksen M, Shafey O. The tobacco atlas. 2nd ed. Atlanta, GA: American Cancer Society, 2006.

18. Dupont P, Reynaud M. Adolescents and tobacco. EMC 37-213B-35.

19. Ministère de la Santé Publique. Santé des adolescents scolarisés: Résultats d'une enquête nationale. Direction de la médecine scolaire et universitaire 2002.

20. Maatoug J, Harrabi I, Gaha R, Bouyahia O, Gaha M, et al. Etude d'intervention sur le tabagisme chez les adolescents dans la région de Sousse, Tunisie. Rev Pneumol Clin 2010;66:179-86.

21. Audrain-McGovern J, Rodriguez D, Tercyak KP, Cuevas J, Rodgers K, et al. Identifying and characterizing adolescent smoking trajectories. Cancer Epidemiol Biomarkers Prev 2004;13:2023-34.

22. Kerjean J, Delbarre AS. Les adolescents et le tabac. Journal de pédiatrie et de puériculture 2005;18:389-393.

23. Collins LM, Graham JW. The effect of the timing and spacing of. observations in longitudinal studies of tobacco and other drug use: temporal design considerations. Drug Alcohol Depend 2002;68(Suppl 1):S85-96.

24. White HR, Pandina RJ, Chen PH. Developmental trajectories of. cigarette use from early adolescence into young adulthood. Drug Alcohol Depend 2002;65:167-78.

25. Barreto SM, Giatti L, Casado L, de Moura L, Crespo C, et al. Smoking exposure among school children in Brazil. Science and Public Health 2010;15(Supl 2):3027-3034.

26. Larson NI, Story M, Perry CL, Neumark-Sztainer D, Hannan PJ. Are diet and physical activity patterns related to cigarette smoking in adolescents? Project EAT. Preventing Chronic Disease: Public Health Research, Practice and Policy 2007;4.

27. Pate RR, Trost SG, Levin S, Dowda M. Sports participation and health-related behaviors among US youth. Arch Pediatr Adolesc Med 2000;154:904-11.

28. Kimm SY, Glynn NW, Obarzanek E, Kriska AM, Daniels SR, et al. Relation between the changes in physical activity and body-mass index during adolescence: a multicentre longitudinal study. Lancet 2005;366:301-7. 
29. Sjoberg A, Halberg L, Hoglund D, Hulthen L. Meal pattern, food choice, nutrient intake and lifestyle factors in The Goteborg Adolescence Study. Eur J Clin Nutr 2003;57:1569-78.

30. Eisenberg ME, Olson RE, Neumark-Sztainer D, Story M, Bearinger LH. Correlations between family meals and psychosocial well-being among adolescents. Arch Pediatr Adolesc Med 2004;158:792-6.
31. Yorulmaz F, Akturk Z, Dagdeviren N, Dalkilic A. Smoking among adolescents: relation to school success, socioeconomic status, nutrition, and self-esteem. Swiss Med Wkly 2002;132:449-54.

32. Alamian A, Paradis G. Individual and social determinants of multiple chronic disease behavioral risk factors among youth. BMC Public Health 2012;12:224. 